\title{
Nissen fundoplikasyonundan yıllar sonra fundusta divertikül gelişmesi: Geç komplikasyon mu? Eşlik eden durum mu?
}

Development of diverticulum in the fundus after Nissen fundoplication: Late complication or accompanying condition?

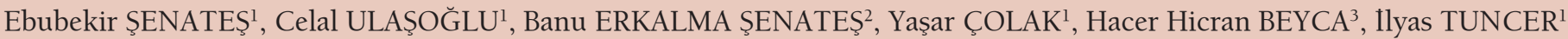

${ }^{1}$ Istanbul Medeniyet Unniversitesi Göztepe Eğitim ve Araștırma Hastanesi Gastroenteroloji Kliniğĭ, Istanbul

${ }^{2}$ Istanbul Üniversitesi Cerrahpaşa Tip Fakültesi, Nefroloji Bilim Dall, Istanbul

${ }^{3}$ Bezmialem Vakıf Üniversitesi Tip Fakültesi, Onkoloji Kliniği, Istanbul

Onsekiz yaşında kadın hasta polikliniğimize reflü yakınmaları (heartburn, ağza acı ekşi su gelmesi) ile başvurdu. Hastaya, 6 yaşındayken medikal tedaviye yanıtsız reflü yakınmaları nedeniyle Nissen fundoplikasyonu operasyonu yapılmış. Takiplerinde yakınmaları gerileyen hasta 6-16 yaşları arasında çeşitli Pediatrik Gastroenteroloji polikliniklerinde takip edilmiş. Hastanın kliniğimizde, yakınmalarının tetkiki amacıyla yapılan üst gastrointestinal endoskopide; özofajit (L.A. Evre A), fundusta divertikül $(2 * 3 * 3 \mathrm{~cm}$ boyutlarında) ve antral gastrit saptandı. Yaklaşık 1.5 yıl önce yapılmış olan endoskopik incelemede (yazılı rapor ve resimlerin değerlendirilmesinde) fundusta patoloji saptanmamiş.

Literatürde Nissen fundoplikasyonuna sekonder erken ve geç komplikasyonlar bildirilmiştir. Erken komplikasyonlar ara-

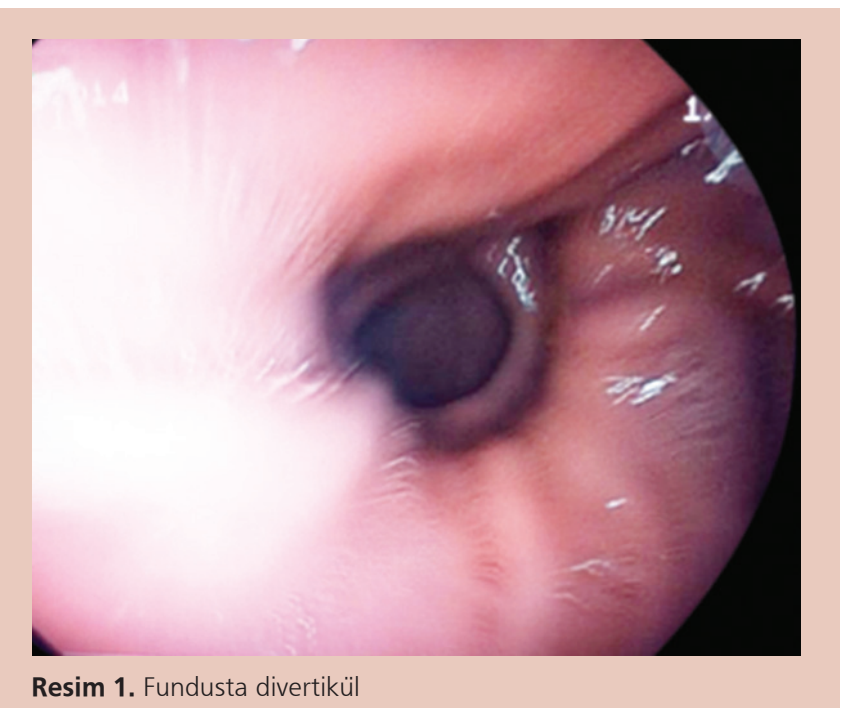

Senateş E, Ulaşoğlu C, Erkalma Şenateş B, et al. Development of diverticulum in the fundus after Nissen fundoplication: Late complication or accompanying condition? Endoscopy Gastrointestinal 2016;24:59-60. sinda özofagus, mide perforasyonu (1), kısa gastrik damarların kesilmesine sekonder kanamalar (2,3), pnömotoraks (1), post-op bulantı kusma (4) bildirilmiştir. Geç komplikasyonlar arasında ise, gaz-şişkinlik sendromu (abdominal distansiyon, erken doyma, bulantı, üst karın ağrısı, flatulans, geğirememe, kusamama gibi semptomları içerir) (5), disfaji (6), diyare ve flatulans $(7,8)$, rekürren heartburn (9), rekürren atipik semptomlar (10) bildirilmiştir.

Ancak internet bazlı yaptığımız literatür araştırmasında daha önce benzer bir vakanın hiç yayınlanmadığını saptadık. Bu hastada da fundusta saptanan divertikülün Nissen fundoplikasyonuna sekonder mi geliştiği veya eşlik eden bir bulgu mu olduğu konusu net değildir. Ancak bu vaka ilginç olduğu için yayınlamak istedik.

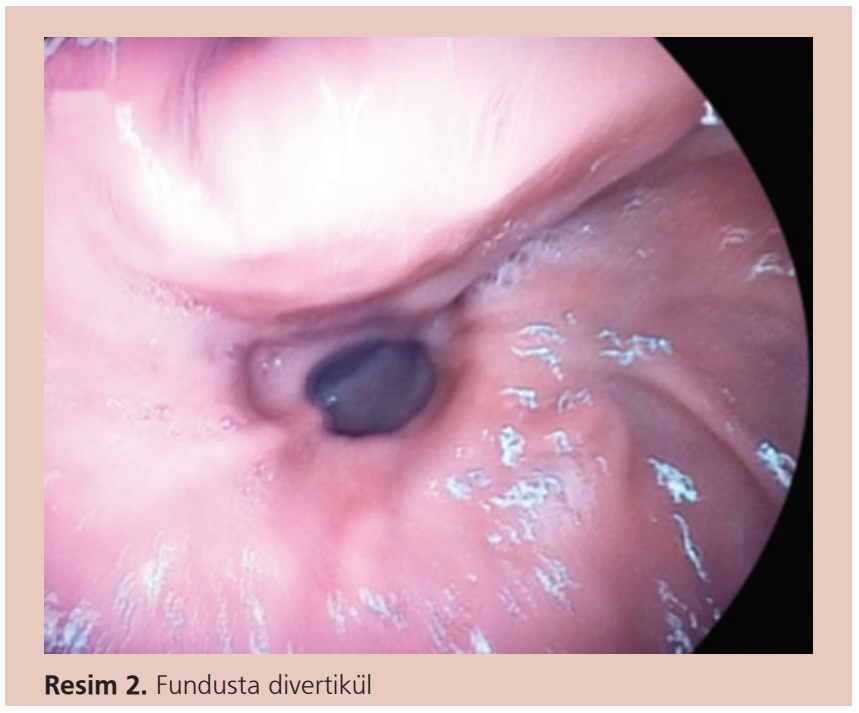

İletişim: Ebubekir ŞENATEŞ İstanbul Medeniyet Üniversitesi, Göztepe Eğitim ve Araştırma Hastanesi, Gastroenteroloji Kliniği, İstanbul, E-mail: ebubekirsenates@yahoo.com Geliş Tarihi: 07.08.2014 Kabul Tarihi: 01.10.2016 

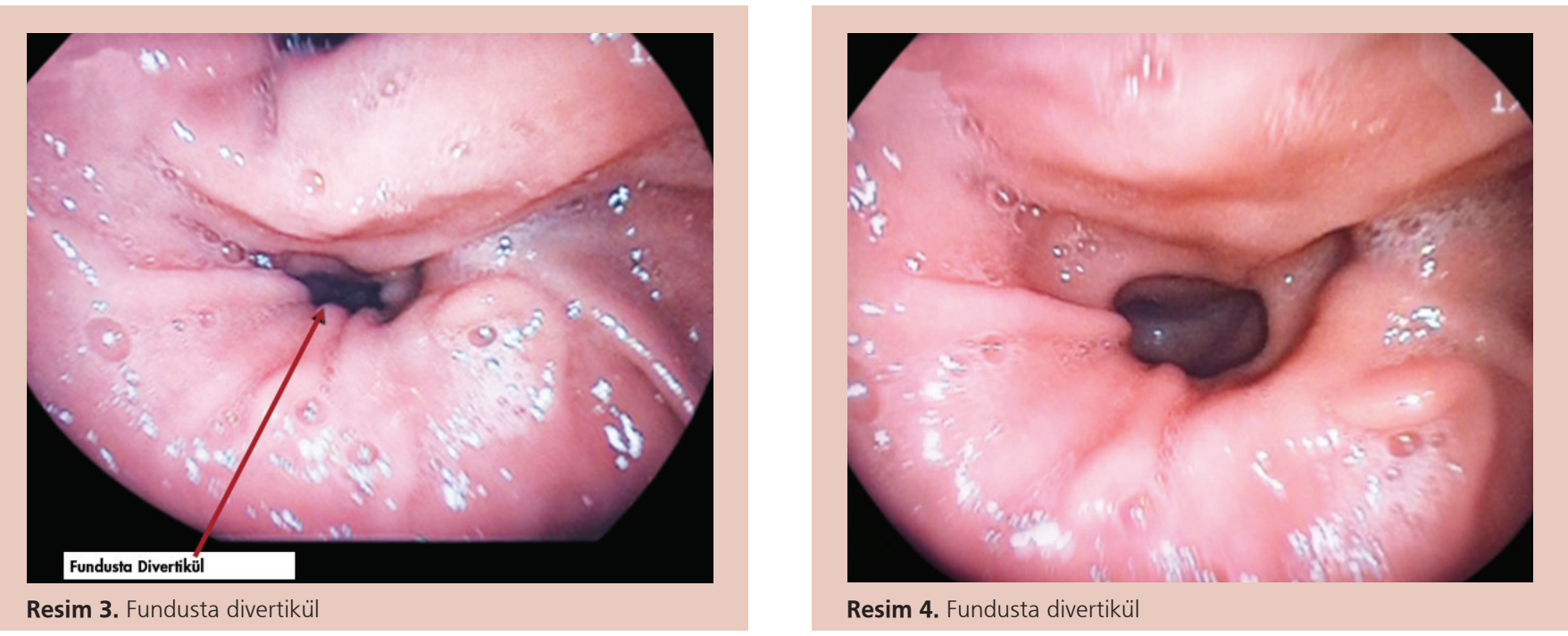

\section{YORUM}

Nissen fundoplikasyonu sonrası erken ve geç dönemde çeşitli komplikasyonlar olabilmektedir. Fundoplikasyonun bozulması ve herninin tekrarı veya postoperatif poş oluşumu da söz konusu olabilir. Bu olguda gözlenen anatomik değişikliğin öncelikle baryumlu mide grafisi ile özelliğinin tam tesbiti lezyonun adının konmasına yardımcı olacaktır.

Prof. Dr. Orhan SEZGIN

Özgün Görüntüler Editörü

\section{KAYNAKLAR}

1. Stefanidis D, Hope WW, Kohn GP, et al. Guidelines for surgical treatment of gastroesophageal reflux disease. Surg Endosc 2010;24:2647-69.

2. Flum DR, Koepsell T, Heagerty P, et al. The nationwide frequency of major adverse outcome in antireflux surgery and the role of surgeon experience, 19921997. J Am Coll Surg 2002;195:611-8.

3. Bizekis $\mathrm{C}$, Kent M, Luketich J. Complications after surgery for gastroesophageal reflux disease. Thorac Surg Clin 2006;16:99-108.

4. Bradshaw WA, Gregory BC, Finley CR, et al. Frequency of postoperative nausea and vomiting in patients undergoing laparoscopic foregut surgery. Surg Endosc 2002;16:777-80.

5. Agency for Healthcare Research and Quality-the Effective Healthcare Program. Comparative effectiveness of management strategies for gastroesophageal reflux disease: an update to the 2005 report 2011. Washington, DC: Agency for Healthcare Research and Quality, 2011.
6. Wo JM, Trus TL, Richardson WS, et al. Evaluation and management of post fundoplication dysphagia. Am J Gastroenterol 1996;91:2318-22.

7. Klaus A, Hinder RA, DeVault KR, et al. Bowel dysfunction after laparoscopic antireflux surgery: incidence, severity and clinical course. Am J Med 2003;114:6-9.

8. Swanstrom L, Wayne R. Spectrum of gastrointestinal symptoms after laparoscopic fundoplication. Am J Surg 1994;167:538-41.

9. Spechler SJ, Lee E, Ahnen D, et al. Long-term outcome of medical and surgical therapies for gastroesophageal reflux disease: follow-up of a randomized controlled trial. JAMA 2001;285:2331-8.

10. Yuksel ES, Vaezi MF. New developments in extraesophageal reflux disease. Gastroenterol Hepatol (N Y) 2012;8:590-9. 